\title{
RS Wave Amplitude Aggregate
}

National Cancer Institute

\section{Source}

National Cancer Institute. RS Wave Amplitude Aggregate. NCI Thesaurus. Code C117793.

An aggregate RS wave amplitude value based on measurements from multiple beats from a single ECG. The method of aggregation, which can vary, is typically a measure of central tendency such as the mean. (CDISC) 